\title{
Obtention de plantes haploïdes chez le melon (Cucumis melo L.) par gynogenèse induite par du pollen irradié
}

\author{
Annie SAUTON, Robert DUMAS de VAULX \\ I.N.R.A., Station d'Amélioration des Plantes Maraîchères, Centre de Recherches d'Avignon, F 84140 Montfa- \\ vet
}

\begin{abstract}
Des plantes haploïdes de melon (Cucumis melo L.) ont été obtenues après pollinisation par du pollen inactivé par irradiation aux rayons $\gamma \mathrm{du} \mathrm{Co}^{60}$ et culture in vitro d'ovules ou d'embryons immatures. Un milieu de culture original a ćté mis au point pour permettre le développement de ces embryons.

Sur deux génotypes possédant des gènes marqueurs, le nombre moyen d'embryons haploïdes obtenus se situe autour de 2,5 pour 100 graines observées.

Le taux d'haploïde a été augmenté par l'apport d'une plus grande quantité de pollen irradié sur le stigmate (pollen de 4 fleurs mâles). A partir d'une dose d'irradiation de $30 \mathrm{Krads}$, on n'observe plus de fécondation normale et donc d'embryons hybrides diploïdes et tous les embryons obtenus ont donné naissance à des plantes haploïdes de phénotype maternel.

Les embryons haploïdes sont facilement reconnaissables par leur forme et position dans la graine, caractéristiques par rapport à des embryons diploïdes normaux de même âge.
\end{abstract}

Mots clés additionnels : Ovule, graine, embryon, rayons $\gamma \mathrm{Co}^{60}$, in vitro.

Haploid plants of muskmelon (Cucumis melo L.) were obtained following pollination with irradiated pollen $\left(\mathrm{Co}^{60} \gamma\right.$-rays) and in vitro culture of ovules or immature embryos. A new culture medium was developed to allow further development of these embryos into plants. Two genotypes, bearing marker genes, were used, and an average of 2.5 haploid embryos per 100 seeds was obtained. Increasing the amount of irradiated pollen (using 4 flower buds) led to an improved haploid rate. $\gamma$-ray doses higher than $30 \mathrm{Krad}$ were necessary to avoid normal fertilization and to obtain only haploid embryos. All the haploid plants showed maternal phenotype. Haploid embryos were characteristic and different from normal diploid embryos of the same age.

Additional key words : Ovule, seed, embryo, $\mathrm{Co}^{60} \gamma$-rays, in vitro.

\section{INTRODUCTION}

Chez le melon, espèce préférentiellement allogame mais sélectionnée comme une autogame, les variétés sont soit des lignées pures soit des hybrides F1. La biologie florale de cette espèce à plantes monoïques ou andromonoïques nécessite un contrôle manuel des autofécondations.

Aussi l'utilisation de l'haplodiploïdisation permettrait à la fois de raccourcir dans le temps et d'alléger le travail de fixation par autofécondation. Par ail- leurs, d'autres utilisations de l'haplodiploïdisation peuvent être envisagées notamment pour étudier l'hérédité de caractères polygéniques.

Quelques rares cas d'obtention de plantes haploïdes ont été signalés dans la famille des Cucurbitacées chez les espèces courge (HAYASE, 1954), concombre (AALDERS, 1958) et pastèque (XUE et al., 1983).

Chez le melon, les premières plantes haploïdes ont été obtenues par Dumas de VAULX (1979) lors d'hybridations interspécifiques entre Cucumis melo L. (espèce diploïde, $2 \mathrm{n}=2 \mathrm{x}=24$ ) et Cucumis ficifolius A. Rich (espèce sauvage tẹ́traplö̈de, $2 \mathrm{n}=4 \mathrm{x}=48$ ). 
Cependant le taux d'haploïdie est faible (3 pour 1000 graines dans le meilleur des cas) et les résultats irréguliers (influence de la saison et du génotype).

Notre objectif était de mettre au point, chez cette espèce, une technique dont le rendement en haploïdes, suffisant et régulier, permettrait son utilisation en sélection. Pour mener à bien ce projet, nous avons choisi, dans un premier temps, d'expérimenter parallèlement les voies de culture in vitro de gamétophytes mâles (androgenèse) et femelles (gynogenèse). En effet, ces techniques sont utilisées pour la production d'haploïdes chez un nombre grandissant d'espèces (VASIL, 1980 ; YANG \& ZHOU, 1982 ; HENRY \& de BUYSER, 1983).

Dans nos essais préliminaires chez le melon, la grande aptitude callogène des tissus somatiques a gêné l'embryogenèse d'origine gamétique mâle ou femelle. Ce même phénomène avait déjà été observé chez le melon par DRYANOVSKA \& ILIEVA (1983) et chez d'autres cucurbitacées (SinHA et al., 1979 ; DRYANOVSKA, 1985).

Les seuls proembryons (environ 16 cellules) que nous ayons obtenus par culture d'anthères sont restés bloqués à ce stade. Chez la tomate, les embryons androgénétiques semblent avoir le même comportement (CHAMBONNET, 1985).

Ces observations nous ont conduit à explorer une autre voie d'haploïdisation : la perturbation du processus normal de fécondation du sac embryonnaire au moyen de pollen dénaturé (gamètes lésés par irradiation ou formation d'un gamète mâle unique). Cette perturbation peut entraîner le développement parthénogénétique de l'oosphère ou d'une autre cellule du sac embryonnaire.

Des cas isolés d'induction de la parthénogenèse ont été signalés après traitement du pollen par des substances antimitotiques (protoxyde d'azote, MONTEZUMA de CARVALHO, 1967 ; colchicine, MONTELONGOESCOBEDO \& ROWE, 1969 ; bleu de toluidine, ILLIES, 1974), ou par irradiation (MAIZONNIER, 1971 ; ECOCHARD et al., 1974 ; PANDEY \& PHUNG, 1982 ; SNAPE et al., 1983 ; POWELl et al., 1983).

RAQUIN, en 1985, a montré, chez le pétunia, qu'une irradiation à fortes doses (60 à $100 \mathrm{Krads}) \mathrm{du}$ pollen aux rayons $\gamma \mathrm{du} \mathrm{Co}^{60}$, permettait d'obtenir environ 2 haploïdes pour 10000 ovules cultivés in vitro. $\mathrm{Ce}$ rendement très faible reste intéressant chez le pétunia oủ l'évènement androgénétique est encore plus rare et conduit dans plus de 90 p. 100 des cas à des plantes triplö̈des à pollen déficient (RAQUIN, 1984).

La technique d'irradiation de pollen semblant la plus performante, nous avons choisi de l'appliquer au melon.

\section{MATÉRIEL ET MÉTHODES}

\section{A. Matériel végétal}

Les parents femelles, ArIzONA \& VIRKA, sont de type andromonoïque et possèdent respectivement, à l'état homozygote, les allèles récessifs gl (glabre) et nsv (résistance au virus de la criblure du melon = Muskmelon Necrotic Spot Virus = MNSV).

Le parent mâle VEDRANTAIS, de type Cantaloup Charentais, possède les allèles dominants correspondants $\left(g l^{+}, n s v^{+}\right)$à l'état homozygote.

Le choix de parents femelles et mâles porteurs de gènes marqueurs est une précaution indispensable pour une détermination aisée de l'origine des embryons obtenus.

\section{B. Protocole expérimental}

\section{La pollinisation}

Les fleurs hermaphrodites sont castrées et ensachées au stade F-1 soit 24 heures avant l'ouverture des pétales et l'anthèse. Les boutons floraux mâles sont prélevés au stade F-1, débarrassés de leurs sépales et pétales puis traités par les rayons $\gamma$ du $\mathrm{Co}^{60}$ dans un irradiateur LEMER prototype 1966. Le débit de dose était de $180 \mathrm{rads} / \mathrm{mn}$ au début de ces expériences en mai 1985. Des doses d'irradiation de $10,30,100$ et 150 Krads ont été utilisées pour la mise au point de la technique de pollinisation alors que 10,30 et $100 \mathrm{Krads}$ ont été appliqués lors des études concernant l'effet de la dose d'irradiation. Pour toutes les autres études, $100 \mathrm{Krads}$ sont employés. Le lendemain de la castration, chaque fleur femelle est pollinisée par le pollen irradié de 2 ou 4 boutons. L'ovaire est traité avec une solution d' $\alpha$ naphtyl acétamide $(1$ p. 100 du produit commercial procarpil-tomates ${ }^{\circledR}$ RHODIAGRI) qui a un effet favorable au développement parthénocarpique des fruits de melon. Enfin les fleurs sont ensachées à nouveau.

\section{La culture in vitro}

Les ovaires sont prélevés 5 à 9 jours après la pollinisation puis désinfectés par trempage pendant 5 minutes dans une solution d'hypochlorite de calcium à 10 p. 100 additionnée de quelques gouttes de Tween 20. Ils sont ensuite rincés 3 fois à l'eau stérile. Les ovules sont extraits et mis en culture par groupe de 20 en boîtes de Pétri (polystyrène de $55 \mathrm{~mm}$ de diamètre).

Les graines, prélevées aseptiquement dans des fruits préalablement désinfectés par flambage, sont ouvertes sous loupe binoculaire ; les embryons en sont extraits et mis en culture.

Le milieu de culture des ovules et des embryons noté E20A comprend :

- les macroéléments et microéléments du milieu $\mathrm{C}$ dont les solutions ont été mises au point pour la culture d'anthères chez le piment (DuMAS de VAuLX et al., 1981). Ils sont utilisés dilués de moitié ;

- les vitamines et acides aminés du milieu $R$ décrits dans le même travail ;

- $\mathrm{Na}_{2}$ EDTA : 18,65 mg/l et $\mathrm{Fe} \mathrm{SO}_{4}: 13,90 \mathrm{mg} / \mathrm{l}$;

- acide B-indolyl acétique (AIA) : $0,01 \mathrm{mg} / 1$;

- Saccharose : $20 \mathrm{~g} / \mathrm{l}$, agar : $10 \mathrm{~g} / 1$.

Le pH est ajusté à 5,9 avant la stérilisation à l'autoclave à $115^{\circ} \mathrm{C}$ pendant 20 minutes.

Les cultures en boîtes de Pétri ou en tubes à essais sont placées en chambre climatisée en photopériode de 12 heures et à la température constante de $25^{\circ} \mathrm{C}$. 


\section{RÉSULTATS}

\section{A. Mise au point de la technique de pollinisation}

Le pollen de la variété VEDRANTAIS irradié à des doses de 10 à $100 \mathrm{Krads}$ est capable de germer in vitro sur le milieu de germination spécifique du pollen de melon comprenant $250 \mathrm{~g} / 1$ de lactose et $50 \mathrm{mg} / 1$ d'acide borique (technique de la goutte pendante). Les tubes polliniques émis par le pollen ainsi irradié sont capables d'atteindre les ovules (observations en fluorescence). Une dose de 150 Krads entraîne l'apparition de tubes polliniques déformés dont la progression dans le style s'arrête très rapidement. Nous avons donc choisi, pour les expérimentations ne concernant pas l'effet de la dose d'irradiation, de traiter le pollen à 100 Krads.

La formation et le développement du fruit sont observés en moyenne chez 35 p. 100 des fleurs pollinisées, le pourcentage de nouaison du génotype VIRKA étant légèrement supérieur à celui du génotype ARIZONA, plus sensible aux variations climatiques.

L'utilisation du procarpil-tomates ${ }^{\circledR}$ permet d'élever le taux moyen de nouaison de 35 à 50 p. 100 .

\section{B. Culture des ovules in vitro}

Les fleurs nouées évoluent normalement : 9 jours après la pollinisation, les jeunes graines sont déjà difficiles à extraire du placenta assez dur. Nous avons donc choisi de prélever et de mettre en culture les ovules 5 à 7 jours seulement après la pollinisation.

\section{Obtention des embryons}

Des embryons apparaissent 3 à 4 semaines après l'initiation de la culture sur le.milieu E20A avec une fréquence moyenne de 1 embryon pour 100 ovules (fig. 1), la plupart des embryons évoluent en plantes. Certains présentent un blocage de l'apex caulinaire. Une observation semblable a été faite sur courgette (DUMAS de VAUI.X, non publié).

Il est bon de souligner que le procarpil-tomates ${ }^{\circledR}$

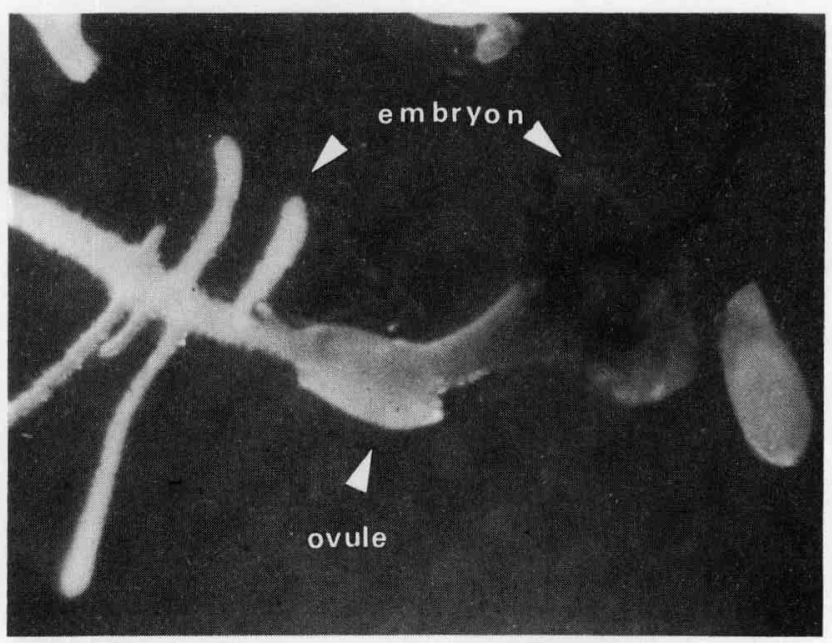

Figure 1

Embryon haplö̈de obtenu à partir d'un ovule cultivé in vitro.

Haploid embryo arising from an ovule cultured in vitro. n'induit pas, à lui seul, la formation d'embryons sur des témoins non pollinisés.

\section{Origine des embryons et niveau de ploidie}

Les embryons issus du parent ARIZONA $(g l)$ sont tous glabres, donc de phénotype maternel. Par ailleurs, le comptage chromosomique, effectué à partir de pointes de racines prélevées in vitro sur les embryons issus des 2 génotypes, montre qu'ils sont tous haploïdes $(\mathrm{n}=12)$ (fig. 2).

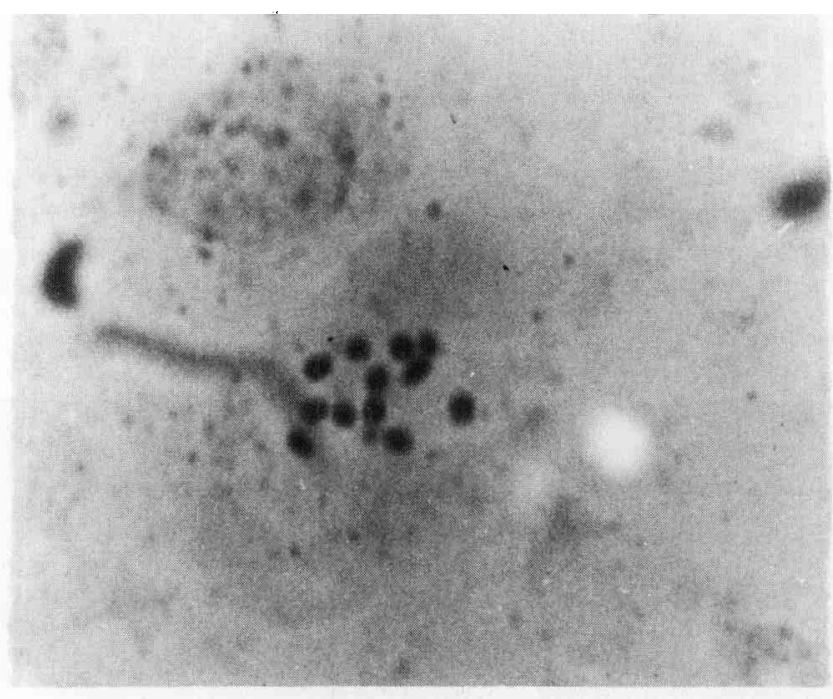

Figure 2

Chromosomes mitotiques d'une plante haploidde de melon $(n=12)$. Mitotic chromosomes of a haploid plant of muskmelon $(n=12)$

Nous pouvons donc conclure que le pollen irradié à 100 Krads n'assure pas une fécondation normale mais induit une parthénogenèse haploïde chez les 2 génotypes.

L'extraction systématique d'environ 500 ovules contenus dans un jeune ovaire de $5 \mathrm{~cm}$ de long est une opération trop fastidieuse et coûteuse en temps; aussi avons-nous laissé les fruits se développer sur la plantemère et prélevé les graines dans des fruits mûrs âgés de 6 semaines. Ces graines, plates et d'apparence externe vides, ne germent ni en terre ni sur des milieux nutritifs. Les embryons qu'elles contiennent doivent donc être prélevés et cultivés in vitro.

\section{Prélèvement des embryons dans les graines immatu- res}

\section{Recherche du stade optimal de prélèvement}

Les graines extraites de fruits âgés de 3 à 4 semaines sont faciles à ouvrir. Elles sont toutes dépourvues d'albumen et 1 à 2 p. 100 d'entre-elles contiennent un embryon solitaire qui est au stade globulaire (1 à $2 \mathrm{~mm}$ de diamètre) ou cordiforme (3 à $6 \mathrm{~mm}$, fig. 3). Placés sur le milieu E20A en boîtes de Pétri, tous les embryons cordiformes et 75 p. 100 des embryons globulaires se développent aussitôt en plantes (fig. 4) qui peuvent être transférées 7 à 15 jours plus tard en tubes à essais sur le même milieu E20A (fig. 5). Envi- 


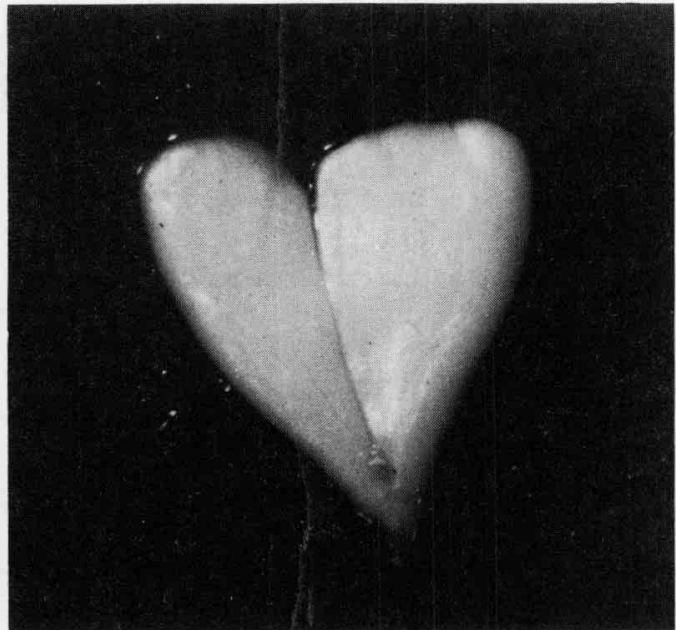

Figure 3

Embryon haploïde cordiforme au moment de son extraction dans la graine ( 3 semaines après la pollinisation).

Heart-shaped haploid embryo at the time of extraction from the seed ( 3 weeks after pollination).

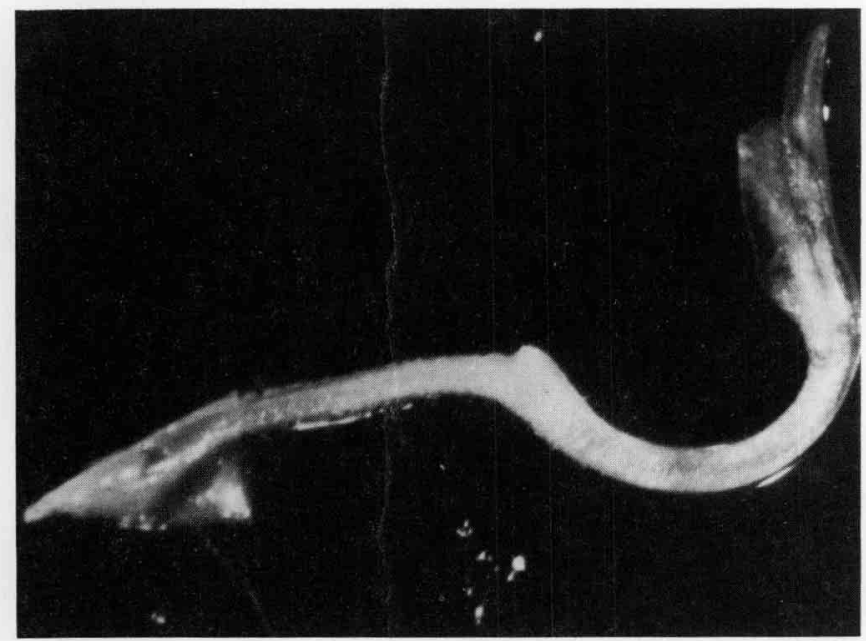

Figure 4

Germination de l'embryon haploïde sur le milieu E20A.

Haploid embryo germination on E20A medium.

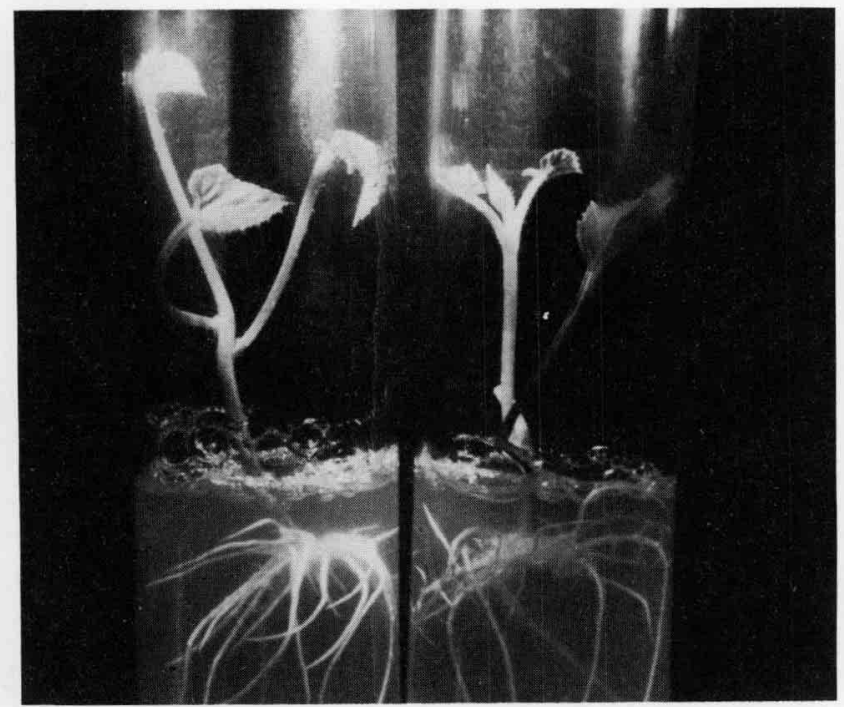

Figure 5

Plantes haploides in vitro. Haploid plants in vitro. ron 25 p. 100 des embryons globulaires ne se développent pas ou donnent des plantes sans apex. Un phénomène semblable est observé chez les haploïdes d'orge (Devaux \& JEAN, 1985).

Le comptage chromosomique réalisé à partir des racines prélevées in vitro montre que toutes les plantes sont haploïdes.

Le stade cordiforme est le stade maximum de développement que puisse atteindre l'embryon haploïde dans la graine dépourvue d'albumen. Ce stade est atteint dans un fruit âgé de 3 semaines mais par la suite, l'embryon haploïde se dessèche et dégénère. Sa reprise in vitro est compromise si le fruit est âgé de plus de 5 semaines au moment de son prélèvement mais certains génotypes à maturité très tardive peuvent faire exception.

\section{Reconnaissance de l'embryon haploïde}

Un embryon haploïde cordiforme âgé de 3 semaines et de taille maximale ne remplit la graine, d'apparence externe plate et vide, qu'au $2 / 3$; ses cotylédons plus ou moins dissymétriques et étalés lui donnent la forme d'un cour (fig. 3).

Un embryon normal diploïde de même âge remplit toute la graine, qui est d'apparence bombée, et ses cotylédons sont superposés.

Donc, si une contamination de pollen survenait lors de la pollinisation par le pollen irradié, ce qui est très rare, l'embryon hybride diploïde obtenu serait facilement reconnu et éliminé.

\section{Les plantes haploïdes obtenues}

Les plantes haploïdes âgées d'environ un mois sont transférées en terre au stade 3 à 4 feuilles. Leur reprise est excellente (fig. 6) à condition de prendre quelques précautions indispensables à la survie de tout matériel issu de culture in vitro. Leur croissance est rapide mais les plantes restent grêles. Les fleurs sont de petite taille et stériles. En fécondation libre, quelques fruits peuvent se former et contenir jusqu'à 10 graines normales.

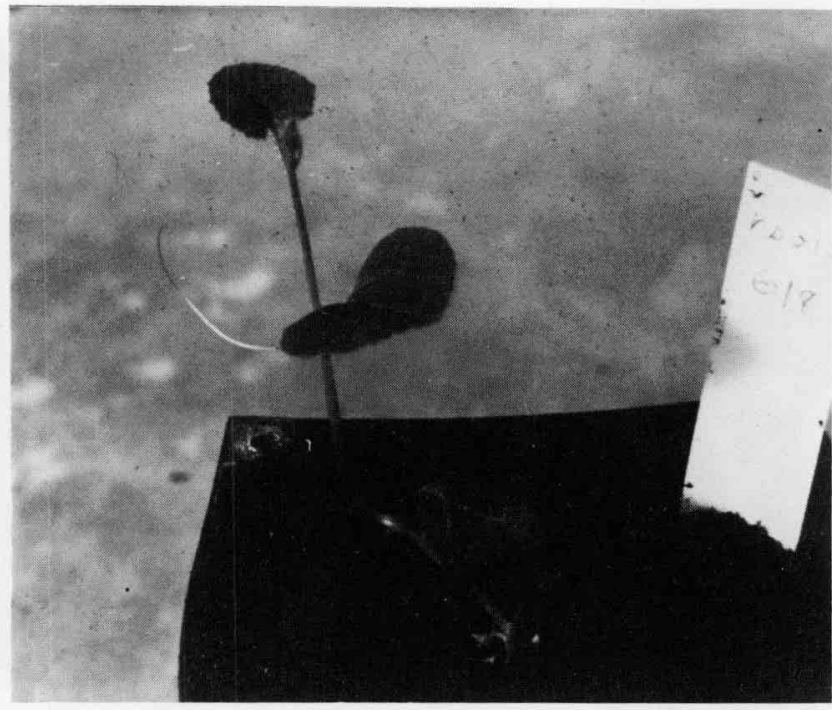

Figure 6

Plante haploide en terre. Haploid plant in soil. 
Les plantes haploïdes issues de VIRKA ont été testées pour la résistance au MNSV: le caractère de résistance s'exprime aussi à l'état haploïde.

\section{E. Influence de quelques facteurs sur le rendement de la méthode}

\section{Effet de la quantité de pollen apportée sur le stig- mate et du génotype}

Lors des premiers essais, le pollen de 2 boutons mâles irradiés à $100 \mathrm{Krads}$ était apporté sur le stigmate. Nous avons testé l'influence d'un apport de pollen plus abondant en pollinisant chaque fleur femelle par le pollen provenant de 4 boutons floraux mâles. En effet, une saturation du stigmate par le pollen et, par conséquent, un très grand nombre de tubes polliniques germant dans le style puis atteignant les ovules, pourrait se traduire par une stimulation de l'induction parthénogénétique dans un plus grand nombre d'ovules.

Nous avons analysé (tabl. 1 et 2) l'influence de 2 facteurs (dose de pollen et génotype) sur les 4 caractères suivants :

- le nombre de graines par fruit,

- le nombre d'embryons par fruit,

- le nombre d'embryons pour 100 graines,

- le pourcentage d'embryons au stade cordiforme.
L'analyse de variance à 2 critères (tabl. 2) montre que, d'une façon générale, il n'y a pas d'interaction entre les 2 facteurs étudiés (dose de pollen et génotype) pour les 4 caractères analysés. Elle met également en évidence, pour ces 4 caractères, des coefficients de variations très importants (25 à $50 \mathrm{p}$. 100).

Une expérimentation basée sur un nombre d'observations beaucoup plus grand semble donc indispensable dans une telle étude.

L'apport d'une grande quantité de pollen (4 boutons mâles) nous a conduit à observer :

- un nombre d'embryons pour 100 graines légèrement plus élevé (tabl. 1) quoique cet effet soit non significatif (tabl. 2) ;

- un nombre de graines par fruit plus important chez les 2 génotypes (effet à la limite de la signification ; probabilité du F égale 7,33 p. 100).

La résultante de ces 2 effets se traduit par un plus grand nombre d'embryons dans les fruits $(12 \mathrm{au}$ lieu de 5,6 chez ARIZONA; 16,3 au lieu de 9,3 chez VIRKA). Cet effet est significatif (tabl. 2).

En ce qui concerne le génotype, nous constatons un effet hautement significatif sur le pourcentage d'embryons au stade cordiforme qui est de 60 à 70 p. 100 chez ARIZONA et 27 à 35 p. 100 seulement chez VIRKA.

Il est intéressant de noter que dans 2 fruits de VIRKA contenant chacun 600 graines, nous avons

TABLEAU

Effet de la dose de pollen irradié sur le nombre de graines et le nombre d'embryons haploïdes chez, 2 génotypes de melon. Influence of dose of irradiated pollen on seed number and haploid embryo number in 2 muskmelon genotypes.

\begin{tabular}{|c|c|c|c|c|c|c|c|c|c|c|}
\hline \multirow{2}{*}{$\begin{array}{c}\text { Dose } \\
\text { de } \\
\text { pollen }\end{array}$} & \multirow{2}{*}{ Génotype } & \multirow{2}{*}{$\begin{array}{c}\text { Nombre } \\
\text { de } \\
\text { fruits }\end{array}$} & \multirow{2}{*}{$\begin{array}{c}\text { Nombre } \\
\text { de } \\
\text { graines }\end{array}$} & \multirow{2}{*}{$\begin{array}{c}\text { Nombre } \\
\text { de } \\
\text { graines } \\
\text { par fruit }\end{array}$} & \multicolumn{3}{|c|}{ Nombre d'embryons haploïdes } & \multirow{2}{*}{$\begin{array}{c}\text { Pourcentage } \\
\text { d'embryons } \\
\text { au stade } \\
\text { cordiforme }\end{array}$} & \multirow{2}{*}{$\begin{array}{c}\text { Nombre } \\
\text { d'embryons } \\
\text { pour } 100 \\
\text { graines }\end{array}$} & \multirow{2}{*}{$\begin{array}{c}\text { Nombre } \\
\text { d'embryons } \\
\text { par } \\
\text { fruit }\end{array}$} \\
\hline & & & & & $\begin{array}{c}\text { Stade } \\
\text { globulaire }\end{array}$ & $\begin{array}{c}\text { Stade } \\
\text { cordiforme }\end{array}$ & Total & & & \\
\hline \multirow{2}{*}{$\begin{array}{c}2 \\
\text { boutons } \\
\text { mâles }\end{array}$} & ARIZONA & 13 & 4600 & $354 \pm 65$ & 22 & 51 & 73 & 69,8 & 1,59 & $5,6 \pm 4,3$ \\
\hline & VIRKA & 4 & 1811 & $453 \pm 105$ & 27 & 10 & 37 & 27 & 2,04 & $9,3 \pm 3,4$ \\
\hline \multirow{2}{*}{$\begin{array}{c}4 \\
\text { boutons } \\
\text { mâles }\end{array}$} & ARIZONA & 4 & 2064 & $516 \pm 71$ & 18 & 30 & 48 & 62,5 & 2,32 & $12 \pm 2,9$ \\
\hline & VIRKA & 18 & 10620 & $590 \pm 160$ & 192 & 102 & 294 & 34,7 & 2,77 & $16,3 \pm 5,6$ \\
\hline
\end{tabular}

TABLEAU 2

Probabilité (en p. 100) des coefficients $F$ de l'analyse de variance avec 2 critères pour 4 caractères. $F$ probability $(\%)$ for analysis of variance with 2 variables for 4 characters.

\begin{tabular}{|c|c|c|c|c|}
\hline & $\begin{array}{l}\text { Nombre } \\
\text { de graines } \\
\text { par fruit }\end{array}$ & $\begin{array}{c}\text { Pourcentage } \\
\text { d'embryons } \\
\text { au stade } \\
\text { cordiforme }\end{array}$ & $\begin{array}{c}\text { Nombre } \\
\text { d'embryons } \\
\text { pour } 100 \text { graines }\end{array}$ & $\begin{array}{c}\text { Nombre } \\
\text { d'embryons } \\
\text { par fruit }\end{array}$ \\
\hline Dose de pollen & 7,33 & 10,15 & 17,22 & 1,76 \\
\hline Génotype & 44,33 & 0,01 & 29,64 & 13,30 \\
\hline Interaction dose pollen $\times$ génotype & 55,74 & 36,59 & 78,15 & 95,85 \\
\hline Coefficient de variation & 23,80 & 32 & 53 & 45,90 \\
\hline
\end{tabular}


TABLEAU 3

Effet de la dose de rayons $\gamma$ sur le contenu des graines d'Arizona (l 000 graines par traitement).

Influence of gamma-ray dose on the contents of seeds of ( $v$. d'Arizona (I 000 seeds per irradiation dose).

\begin{tabular}{|c|c|c|c|c|c|}
\hline $\begin{array}{c}\text { Dose } \\
\text { d'irradiation } \\
\text { Krads }\end{array}$ & $\begin{array}{c}\text { Nombre } \\
\text { d'embryons } \\
\text { type } \\
\text { diploide }\end{array}$ & $\begin{array}{c}\text { Nombre } \\
\text { d'embryous } \\
\text { lype haploïde } \\
\text { (cordiforme + } \\
\text { globulaire) }\end{array}$ & $\begin{array}{l}\text { Nombre } \\
\text { d'embryons } \\
\text { globulaires } \\
+ \text { albumen }\end{array}$ & $\begin{array}{c}\text { Nombre } \\
\text { d'albumen } \\
\text { seul }\end{array}$ & $\begin{array}{c}\text { Nombre } \\
\text { d'embryons } \\
\text { avortés }\end{array}$ \\
\hline 10 & 3 & 8 & 2 & 30 & 67 \\
\hline 30 & 0 & 18 & 0 & 1 & 39 \\
\hline 100 & 0 & 16 & 0 & 0 & 32 \\
\hline
\end{tabular}

trouvé jusqu'à 37 embryons (globulaires + cordiformes). Donc dans les conditions de cette expérience et à 2 reprises, plus de 5 p. 100 des ovules ont présenté un développement parthénogénétique.

\section{Effet de la dose d'irradiation}

Chaque fleur femelle d'ARIzona a été pollinisée avec le pollen de 4 boutons mâles. Pour chaque traitement d'irradiation, le contenu de 1000 graines d'ARIZONA a été observé.

Les résultats de ces observations présentés dans le tableau 3 montrent qu'une dose d'irradiation de 30 Krads ne permet pas une fécondation normale et induit une parthénogenèse haploïde d'intensité comparable à celle obtenue avec du pollent irradié à 100 Krads.

Le pollen irradié à $10 \mathrm{Krads}$ peut assurer une fécondation normale et donner quelques embryons de type diploïde d'apparence normale. Nous constatons aussi la formation d'un très grand nombre d'embryons avortés ou d'un albumen, associé ou non à un embryon bloqué au stade globulaire. Ces structures doivent résulter d'une perturbation plus ou moins accentuée du processus normal de fécondation. Le pollen irradié à $10 \mathrm{Krads}$ est également inducteur de parthénogenèse haploïde mais le nombre d'embryons obtenus est faible ( 0,8 pour 100 graines). Cet effet dit « effet HeRTWIG » a déjà été signalé chez les végétaux (PANDey \& Phung, 1982).

\section{CONCLUSION}

Le seuil de radiosensibilité du pollen de melon aux rayons $\gamma$ est comparable à celui du tabac, de la tomate, du pois, du maïs et se situe entre 10 et 30 Krads. Ce seuil est plus élevé pour le pétunia (60 Krads). La fréquence de l'induction parthénogéné- tique s'avère très intéressante $(2,5$ embryons haploödes pour 100 graines) : elle est supérieure à celle obtenue chez le pétunia (RAQUiN, 1985). Son intensité dépend de la quantité de pollen germant sur le stigmate et donc du nombre de tubes polliniques présents dans le style.

Le prélèvement des embryons directement dans les graines permet de s'affranchir des problèmes de culture directe de gamétophytes in vitro, non encore mâ̂trisés chez les Cucurbitacées. Cette culture d'embryons immatures est à rapprocher quant à sa facilité d'emploi de celle utilisée à grande échelle chez l'orge pour obtenir des plantes haploïdes par la technique « bulbosum » (DEVAUX \& JEAN, 1985).

Tous les embryons que nous avons obtenus sont haploïdes; leur morphologie, spécifique de leur niveau de ploïdie, permet de les reconnaître dès l'ouverture des graines. Leur croissance in vitro est rapide sur le milieu E20A et leur reprise en terre ne pose pas de problème particulier.

D'autres facteurs susceptibles d'avoir une influence sur la fréquence du phénomène d'induction (saison, génotype) sont en cours d'étude. L'efficacité de cette technique a déjà été démontrée sur une gamme de génotypes.

Cette technique permet d'envisager dès à présent l'utilisation de l'haploïdie dans les schémas de sélection du melon.

Ce travail a été réalisé dans le cadre de la convention de Recherche I.N.R.A.-G.I.E. ClauSE/LimAGRAIN.

Reçu le 19 aô̂t 1986 Accepté le 4 décembre 1986.

\section{REMERCIEMENTS}

Les irradiations de pollen ont pu être effectuées à la Station de Zoologie de l'I.N.R.A.-Montfavet grâce à la disponibilité et à la gentillesse de Messieurs Barthes, Causse et Poitout ; nous leur en sommes reconnaissants. 


\section{RÉFÉRENCES BIBLIOGRAPHIQUES}

Aalders L. E., 1958. Monoploidy in cucumbers. J. Hered., 49. 41-44.

Chambonnet D., 1985. Culture d'anthères in vitro chez 3 solanacees maraîchères: le piment /Capsicum annuum L.), l'aubergine (Solanum melongena $L$.), la tomate (Lycopersicon esculentum Mill.) et obtention de plantes haploides. Thèse (Dr. d'université), Universite des Sciences et Techniques du Languedoc, Montpellier, $90 \mathrm{p}$. + annexes.

Devaux P., Jean R., 1985. Influence du mois et de la technique de castration dans la réussite de l'haploïdisation de l'orge par la méthode bulbosum. Agronomie, 5 (9), 795-800.

Dryanovska O. A., 1985. Induced callus in vitro from ovaries and anthers of species from Cucurbitaceae family. C. R. Acad. Bulgare Sci., 38 (9), 1243.

Dryanovska O. A., Ilieva I. N., 1983. In vitro anther and ovule cultures in muskmelon (Cucumis melo L.). C. R. Acad. Bulgare Sci., 36 (8), 1107-1110.

Dumas de Vaulx R., 1979. Obtention de plantes haploïdes chez le melon (Cucumis melo L.) après pollinisation par Cucumis ficifolius A. Rich. C. R. Acad. Sci., Paris, 289, 875-878.

Dumas de Vaulx R., Chambonnet D., Pochard E., 1981. Culture in vitro d'anthères de piment (Capsicum annuum L.) : amélioration des taux d'obtention de plantes chez différents génotypes par des traitements à $+35^{\circ} \mathrm{C}$. Agronomie, 1 (10), 859-864.

Ecochard R., Merkx G., Matteoli M., 1974. Parthenogenesis induced by specific radioinactivation of the male gamete. Proc. First Int. Symp., Guelph (CAN), 1974/06/10-14 ; in : Haploids in Higher Plants, advances and potential, Ed. KASHA K. J., 136.

Hayase H., 1954. Cucurbita crosses. Occurrence of a haploid twin pair from a F1 progeny of C. maxima $\times C$. moschata. Jap. J. Breed, 4, 55

Henry Y., de Buyser J., 1983. Androgenèse chez le blé tendre: Analyse théorique et utilisation en sélection. Thèse (Dr. d'Etat), Sciences Naturelles, Université de Paris-Sud, Centre Orsay, 132 p. + annexes.

Illies Z. M., 1974, Induction of haploid parthenogenesis in aspen by postpollination treatment with toluidine-blue. Silvae Genetica, 23 (6), 221-226.
Maizonnier D., 1971. Utilisation de plantes haploïdes pour l'analyse du caryogramme de Petunia Hybrida. Hort. Ann. Amélior. Plantes, 21, 257-264

Montelongo-Escobedo H., Rowe P. R., 1969. Haploid induction in potato : cytological basis for the pollinator effect. Euphytica, 18, 116-123.

Montezuma de Carvalho J., 1967. The effect of $\mathrm{N}_{2} \mathrm{O}$ on pollen tube mitosis in styles and its potential significance for inducing haploidy in potato. Euphytica, 16, 190-198.

Pandey K. K., Phung M., 1982. "Hertwig effect » in plants : induced parthenogenesis through the use of irradiated pollen. Theor. Appl. Genet., 62, 295-300.

Powell W., Caligari P. D. S., Hayter A. M., 1983. The use of pollen irradiation in barley breeding. Theor. Appl. Genet., 65, 73-76.

Raquin C., 1984. Etude de l'androgenèse chez Petunia hybrida (hort.) et recherche des conditions d'obtention de plantes haploides. Thèse (Dr. d'Etat), Sciences Naturelles, Université de ParisSud, Centre Orsay, 138 p.

Raquin C., 1985. Induction of haploid plants by in vitro culture of petunia ovaries pollinated with irradiated pollen. Z. Pflanzenzüchtg., 94, 166-169.

Sinha S., Jha K. K., Roy R. P., 1979. In vitro development of callus from anthers in Luffa cylindrica. Curr. Sci., 48 (3), 120-121.

Snape J. W., Parker B. B., Simpson E., Ainsworth C. C., Payne P. I., Law C. N., 1983. The use of irradiated pollen for differential gene transfer in wheat (Triticum aestivum). Theor. Appl. Genet., $65,103-111$

Vasil I. K., 1980. Androgenetic haploids. Int. Rev. of Cytol., supp. IIA, 195-223.

Xue G. R., Yu W. Y., Fei K. W., 1983. Watermelon plants derived by in vitro anther culture. Plant Physiol. Commun. (CHN), (4), 4042 .

Yang H. Y., Zhou C., 1982. In vitro induction of haploid plants from unpollinated ovaries and ovules. Theor. Appl. Genet., 63, 97104. 